\title{
Health promotion: An integral discipline of public health
}

\author{
Sanghamitra Pati ${ }^{1}$,Abhimanyu Singh Chauhan ${ }^{2}$
}

${ }^{1}$ Additional Professor, ${ }^{2}$ Program Associate, Indian Institute of Public Health, Bhubaneswar, Odisha, India.

\section{Abstract}

Health promotion is the process of enabling people to increase control over and to improve their health and is emerging as a critical domain of public health. Over the last two decades, the medical model of health care, with its reliance upon clinically oriented experts, has begun a subtle shift that highlights towards a participatory model of health promotion emphasizing healthful lifestyles and healthy communities. This health promotion movement demands public health professionals to create alliances with other disciplines which would ultimately strengthen a holistic model of health as envisaged by World Health Organization. Health promotion encompasses five key strategies with health communication and education as cornerstones. Although developed countries have incorporated health promotion activities as an integral component of their public health system and initiated health promotion education systematically, developing countries are yet to adopt the same. The present paper attempts to explore the importance of health promotion as a core discipline and tool in advancing public health education, research and practice. It further illustrates few health promotion models that have been adopted and practiced for community health development. The paper advocates for stronger recognition of health promotion as an integral entity and incorporation of health promotion in all domains of public health.

Keywords: Health promotion, South-East Asia, Communication, Health education, Public health.

\section{Introduction}

The health status of populations across the world leaves much to be desired despite technological and social growth. Although, significant achievements have been made in the improvement of population health in the last six decades, the health outcomes remain inadequate. ${ }^{1}$ The acceptance of this yawning gap between our capabilities and the actual reality of the health situation has focused the attention of governmental and non-governmental agencies on rebuilding public health. Currently some of the important health care challenges are co-existent with substantial burdens of infectious diseases, reproductive and child health problems, nutritional deficiencies, chronic diseases, and injuries. ${ }^{2}$ More so, several adverse social determinants along with behavioral risk factors like smoking, oral tobacco consumption, and alcohol and substance abuse aggravate the situation. ${ }^{3}$ In this context, health promotion is emerging as a viable sustainable strategy and tool for comprehensive and equitable health development and it holds considerable potential for spearheading public health globally. ${ }^{4}$

Health promotion as the name suggests is linked to health and its promotion, associated with interventions. It offers a public health practitioner the means by which health can be improved by behavioral changes that require effort from the patient and/or engaging in community-based intervention

\section{Practice points}

- Health promotion is a critical domain of public health which enables people to increase control over and improve their own health.

- A shift has begun from medical model of health care towards a participatory model of health promotion emphasizing healthy lifestyles and healthy communities.

- To facilitate participatory approach, health promotion activity heavily relies on health education and communication.

- Enhancing alliances and networking with various healthcare and teaching organizations involved in health promotion activities are essential to improve health of the population.

- Public health education and training has to be regeared through multifaceted capacity building in the countries of South East Asia region.

that enables the easy choice to be the healthy choice. The ideals of health promotion are based on the question "what causes good health?' and 'what factors or determinants are linked to health and which of these are modifiable?', and indeed 'how are they modifiable?' This salutogenic

Correspondence: Dr. Sanghamitra Pati, Indian Institute of Public Health, JSS Software Technology Park, Patia, Bhubaneswar, Odisha 751024, India. Email:sanghamitra.pati@iiphb.org. 
approach focuses on factors that support human health and well-being, rather than on factors that cause disease. This perspective is broader as compared to the traditional preventive and curative approach. ${ }^{5}$ Health promotion initiatives focus on assisting communities or populations to gain greater control over their environment and the conditions that affect their lives, and are designed to include these groups in the strategies for change. The goal of health promotion is to empower individuals and communities to achieve the highest possible levels of well-being available to them. As individuals live longer, health promotion activities are becoming increasingly more important; consequently, globally there has been strong focus on promoting healthy behaviors. Common health promotion activities include adherence to healthy behaviors such as consumption of low-fat and low-cholesterol diets, regular exercise, smoking cessation and moderate consumption of alcohol. $^{6}$

Health promotion, because of its interdisciplinary nature and its person-centered and population-based approaches, sits at odds with the traditional disease and system-based public health teaching models. The discipline of health promotion is relatively young compared to the more established and wider field of public health with which it is closely aligned. However, many of the principles and practices of health promotion have been integral to medicine in its broader sense since the days of Hippocrates. There are few healthcare professionals of whatever discipline, whose work does not involve some elements of health promotion. The aim of this paper is to highlight the importance of health promotion for those working in the public health system and emphasizing a sound understanding of health promotion and its relevance to their day-to-day practice.

\section{Defining health promotion}

The underlying concept for modern health promotion can be traced back to the Alma Alta declaration in $1978{ }^{7}$, which reaffirms the World Health Organization's definition of health as "a state of complete physical, mental and social well-being and not merely the absence of disease or infirmity. ${ }^{8}$ Since then, health promotion has gradually become accepted as a vital and integral part of public health, and is now universally perceived as referring to a holistic field of overlapping activity on primary, secondary and tertiary levels encompassing health education, lifestyle and preventative approaches. The first International Conference on Health Promotion in Ottawa in 1986 presented a charter for action to achieve Health for All by the Year 2000 and beyond. ' Health Promotion has come a long way with several global conferences on health promotion taking place ever since, the sixth and the latest one was held at the Bangkok in 2005, the outcome of which is well known as the 'Bangkok Charter for health promotion in a globalized world'. 'Moving beyond the traditional ailment and injury treatment and health education of people, health promotion focuses primarily on all determinants of health such as physical, social, political, economic etc. and involves activities, e.g. promotion of healthy lifestyles, healthy living, good eating practices, healthy environment, etc. Intensified focus on 'healthy settings' approach has paved the way for multi-sectoral participation and partnerships with governmental and non-governmental organizations. The definition of health promotion provided in the Ottawa Charter is the most widely accepted definition of health promotion. In the Ottawa Charter, health promotion is defined as: "The process of enabling people to increase control over, and to improve, their health'.

As stated in the Ottawa Charter, a health promotion approach views health as a resource for everyday life, with fundamental requirements. ${ }^{7}$ These requirements include peace, shelter, education, food, income, a stable eco-system, sustainable resources, social justice and equity. There are five key strategies in the promotion of optimal health, as laid out in the Ottawa Charter for Health. ${ }^{7}$ These are building healthy public policy, creating supportive environments, strengthening community action, developing personal skills and reorienting health services. This was important in encouraging a move towards a more holistic socioecological model of health, reflecting a focus on 'Salutogenisis' or health creation. ${ }^{5}$ This focus differs from the 'pathogenic' perspective of the more traditional public health and community medicine approaches, in which the focus is on disease or illness or its prevention or treatment, that most often dominate interventions. Adoption of a salutogenic perspective highlights the importance of starting from a consideration of how health is created and maintained through community-based health promotion.

\section{Principles for health promotion}

The World Health Organization determined the principles for health promotion as population health focused, social determinants focused, able to combine a variety of methods, building collaborative partnerships and health workforce focused. ${ }^{10}$ Health promotion has been widely practiced as a strategy to improve the health status of the community. In a study in schools of rural Uganda, there is a significant change in the oral hygiene practices among the children after addressing oral health through health promotion in schools. ${ }^{11}$ Similarly, in an intervention in 10 schools in Canadian province of Alberta, through Comprehensive School Health (CSH) programme, a significant difference was observed among students gone through $\mathrm{CSH}$ than the rest of the province. ${ }^{12}$ In the Stanford Five-City Project, cardiovascular risk knowledge were found in all communities. ${ }^{13}$ This community-based cardiovascular disease prevention programme showed sustained effects; both coronary heart disease and all-cause mortality risk scores were maintained or continued to improve in treatment cities. In many interventions other than knowledge outcome, health promotion has been shown to positive influence on health behaviors and health outcomes. ${ }^{14-21}$ 


\section{How health promotion differs from the traditional approaches}

Apart from health promotion there are a number of other approaches used to guide to development interventions, policies and programmes, addressing health related issues. For example:

(i) Population health aims to improve health inequalities among population groups by examining and acting upon a broad range of factors and conditions that determine health. The main interventions used by population health are societal-level policies affecting the health of entire population (e.g. increasing tobacco taxes). ${ }^{22}$ The impact of these policies is monitored through the use of large-scale data sets. ${ }^{23}$ Unlike health promotion, population health does not place as much emphasis on strategies promoting individual and community level change, such as education, organizational change and community mobilization.

(ii) Disease prevention aims at prevention of chronic disease contributing to premature mortality. Health promotion has a number of features and values that distinguish it from traditional disease prevention efforts, and the strategy focuses on assets and strengths as well as risk factors and conditions, adopts participatory approaches that build the capacity of individuals and communities to address their health concerns, and highlights the social, economic and environmental causes of health and illness. Disease prevention initiatives, by contrast, focus mainly on modifying the health behavior of individuals. ${ }^{24-25}$

(iii) Harm reduction comprises of actions which decreases the adverse health, social and economic consequences of engaging in high-risk behavior without requiring abstinence. ${ }^{26-30}$ Health promotion utilizes many of the same actions and strategies employed by harm reduction; however, its focus is much broader than high-risk behaviors. ${ }^{31-33}$

\section{Health promotion vs. health education and communication}

In its endeavor to facilitate behavioral change for better health and making healthy choice the easy choice, health promotion activity heavily relies on health education and communication. Health education comprises consciously constructed opportunities for learning involving some form of communication designed to improve health literacy, including improving knowledge, and developing life skills which are conducive to individual and community health. ${ }^{14}$ Health education is not only concerned with the communication of information, but also with fostering the motivation, skills and confidence (self-efficacy) necessary to take action to improve health. It includes the communication of information concerning the underlying social, economic and environmental conditions impacting on health, as well as individual risk factors and risk behaviors, and use of the health care system. ${ }^{34,35}$ Thus, health education may involve the communication of information, and development of skills which demonstrates the political feasibility and organizational possibilities of various forms of action to address social, economic and environmental determinants of health. In the past, health education was used as a term to encompass a wider range of actions including social mobilization and advocacy. ${ }^{36,37}$ These methods are now encompassed in the term health promotion.

Health communication encompasses the study and use of communication strategies to inform and influence individual and community decisions that enhance health. It links the domains of communication and health and is increasingly recognized as a necessary element of efforts to improve personal and public health. ${ }^{38}$ Health communication can contribute to all aspects of disease prevention and health promotion and is relevant in a number of contexts, including health professional-patient relations; individuals' exposure to, search for, and use of health information; individuals' adherence to clinical recommendations and regimens; construction of public health messages and campaigns; dissemination of individual and population health risk information, that is, risk communication; images of health in the mass media and the culture at large; education of consumers about how to gain access to the public health and health care systems; and development of Tele-health applications. ${ }^{39-42}$

\section{Health promotion in South-East Asian countries}

Health promotion resulted in the dramatic change in the health situation in the South-East Asian region. ${ }^{43}$ In Indonesia, government has taken initiative to provide primary care at the village level, through Posyandus, an integrated health post, which is managed by the village people. These Posyandus are the center for health education. Since health education can be considered as a part of health promotion, this initiative is considered as the major health promotion movement in the country. ${ }^{44}$ Although creating awareness regarding use of condom publicly is still considered to be culturally difficult in the country. ${ }^{45}$ Myanmar is suffering from the constrained health promotion efforts since the health promotion is not under the priority of the government and hence suffering from the non-availability of the infrastructure. ${ }^{46}$ Non Government Organizations (NGOs) are also not well encouraged in the country which is also a major factor of neglected health promotion initiatives in the country. ${ }^{46}$ Thailand on the other hand had achieved much in their health promotion activities, mainly in the area of HIV/AIDS. NGOs are well organized in the country which resulted in the improvement in the HIV/AIDS status of the country. ${ }^{47}$ Development of 
associations like, ASH (The Thai Association on Smoking and Health), has had influence on the tobacco control legislation of the country. Thailand has also come up with a master plan for social development and Thai Health Promotion Foundation which encourages and strengthens the local organizations for community empowerment. ${ }^{48} \mathrm{Few}$ models discussed above from the Thailand and Indonesia could be considered as a way forward in health promotion in South East Asian countries, but still majority of the countries lacks the proactive role of the government in the area of health promotion like Myanmar.

\section{Conclusion}

Health promotion is a diverse and growing field of public health. While education in health promotion is vital, there needs to be a strong emphasis on health promotion practice as well with special consideration to effective communication. Enhancing alliances and networking with various healthcare and teaching organizations involved in health promotion activities are essential to improve health of the population. Public health education and training has to be re-geared through multifaceted capacity building in the countries of South East Asia region.

\section{References}

1. John TJ, Dandona L, Sharma VP, Kakkar M. Continuing challenge of infectious diseases in India. Lancet 2011;377:252-69.

2. Paul VK, Sachdev HS, Mavalankar D, Ramachandran P, Sankar MJ, Bhandari N, et al. Reproductive health, and child health and nutrition in India: meeting the challenge. Lancet 2011;377:332-49.

3. Patel V, Chatterji S, Chisholm D, Ebrahim S, Gopalakrishna G, Mathers C, et al. Chronic diseases and injuries in India. Lancet 2011;377:413-28.

4. Riegelman RK, Garr DR. Evidence-Based public health education as preparation for medical school. Acad Med 2008; 83:321-6.

5. Antonovsky A. The Salutogenic Model as a theory to guide health promotion. Health Promot Int 1996;11:11-8.

6. Stephenson A. A Textbook of General practice. $2^{\text {nd }}$ edition. London: Hodder Arnold, 2004.

7. WHO. Ottawa Charter for Health Promotion. Geneva: World Health Organization, 1986.

8. WHO. Definition of health. New York: World Health Organization, 1946.

9. WHO. The Bangkok Charter for Health Promotion in a Globalized World. Sixth Global Conference on Health Promotion. Bangkok: World Health Organization, 2005.

10. WHO. Health Promotion: A Discussion Document on the Concepts and Principles. Copenhagen: World
Health Organization, 1986.

11. Macnab A, Kasangaki A. 'Many voices, one song': a model for an oral health programme as a first step in establishing a health promoting school. Health promot int 2012;7:63-73.

12. Fung C, Kuhle S, Lu C, Purcell M, Schwartz M, Storey $\mathrm{K}$, et al. From 'best practice' to 'next practice': the effectiveness of school-based health promotion in improving healthy eating and physical activity and preventing childhood obesity. Int J Behav Nutr Phys Act 2012;9:27.

13. Winkleby MA, Taylor CB, Jatulis D. The long-term effects of a cardiovascular disease prevention trial: the Stanford Five-City Project. Am J Public Health 1996;86:1773-9.

14. Stewart-Brown $\mathrm{S}$. What is the evidence on school health promotion in improving health or preventing disease and, specifically, what is the effectiveness of the health promoting schools approach? www.euro.who.int/_data/assets/pdf_file/0007/74653/ E88185.pdf(accessed May 2012)

15. Murray NG, Low BJ, Hollis C, Cross AW, Davis SM. Coordinated school health programs and academic achievement: a systematic review of the literature. $J$ Sch Health 2007;77:589-600.

16. Lister-Sharp D, Chapman S, Stewart-Brown S, Sowden A. Health promoting schools and health promotion in schools: two systematic reviews. Health Technol Assessment 1999;3:1-207.

17. Wanjiru M, Flisher AJ. Evaluations of health promoting schools: a review of nine studies. Health Promot Int 2004:19:357-68.

18. Rietmeijer CA, Kane MS, Simons PZ, et al. Increasing the use of bleach and condoms among injecting drug users in Denver: outcomes of a targeted, communitylevel HIV prevention program. AIDS 1996;10:291-8.

19. Smedley B, Syme L, eds. Promoting Health: Intervention Strategies from Social and Behavior Research. Washington, DC: National Academy Press, 2000.

20. Lefebvre RC, Harden EA, Zompa B. The Pawtucket Heart Health Program, III: social marketing to promote community health. RI Med J. 1988;71:27-30.

21. Biener L, Harris JE, Hamilton W. Impact of the Massachusetts tobacco control programme: population based trend analysis. BMJ2000;321:351-4.

22. WHO. WHO Framework Convention on Tobacco Control. Geneva: World Health Organization, 2003.

23. William N. Evans, Jeanne S. Ringel, Diana Stech. Taxes and Public Policy to Discourage Smoking. Cambridge, USA: MIT Press, 1999. 
24. Sorensen G, Emmons K, Hunt MK, Johnston D. Implications of the results of community intervention trials. Annu Rev Public Health 1998; 19:379-416.

25. Kelly JA. Community-level interventions are needed to prevent new HIV infections. Am J Public Health 1999;89:299-301.

26. Cheadle A, Beery W, Wagner E, Fawcett S, Green L, Moss D, et al. Conference report: community-based health promotion-state of the art and recommendations for the future. Am J Prev Med. 1997;13:240-3.

27. Feinleib M. Editorial: new directions for community intervention studies. Am J Public Health 1996; $86: 1696-7$.

28. Green LW. Community health promotion: applying the science of evaluation to the initial sprint of a marathon. Am JPrev Med 1997;13:225-8.

29. Koepsell TD, Diehr P, Cheadle A, Kristal A. Invited commentary: symposium on community intervention trials. Am J Epidemiol 1995;142:594-9.

30. Luepker RV, Murray DM, Jacobs DR Jr, Mittelmark MB, Bracht N, Carlaw R, et al. Community education for cardiovascular disease prevention: risk factor changes in the Minnesota Heart Health Program. Am J Public Health 1994;84:1383-93.

31. Schooler C, Farquhar JW, Flora JA. Synthesis of findings and issues from community prevention trials. Ann Epidemiol. 1997; 7:54-68.

32. Susser M. Editorial: the tribulations of trialsintervention in communities. Am J Public Health 1995;85:156-8.

33. Winkleby MA. The future of community-based cardiovascular disease intervention studies. $\mathrm{Am} \mathrm{J}$ Public Health 1994;84:1369-72.

34. McLeroy K, Bilbeau D, Steckler A, Ganz K. An ecological perspective on health promotion programs. Health Educ Q 1988; 15:351-77.

35. Stokols D. Translating social ecological theory into guidelines for community health promotion. Am J Health Promot 1996; 10:282-98.

36. Person B, Cotton D. A model of community mobilization for the prevention of HIV in women and infants. Public Health Rep 1996;111:89-98.

37. Stillman F, Hartman A, Graubard B, Graubard B, Gilpin E, Chavis D, et al. The American Stop Smoking Intervention Study: conceptual framework and evaluation design. Eval Rev 1999; 23:259-80.

38. Schiavo R. Health Communication: From theory to practice. San Francisco: Jossey-Bass, 2011.

39. Kegeles SM, Hays RB, Coates TJ. The Mpowerment Project: a community-level HIV prevention intervention for young gay men. Am J Public Health. 1996; 86:1129-36.

40. Richard L, Potvin L, Kishchuk N, Prlic H, Green LW. Assessment of the integration of the ecological approach in health promotion programs. Am J Health Promot 1996; 10:318-28.

41. Farrelly M, Healton CG, Davis KC, Messeri P, Hersey JC, Haviland L. Getting to the truth: evaluating national tobacco counter marketing campaigns. Am J Public Health 2002;92:901-7.

42. Murray DM. Design and analysis of community trials: lessons from the Minnesota Heart Health Program. Am JEpidemiol 1995;142:569-75.

43. Mukhopadhyay A. South Asia's health Promotion Kaleidoscope. Promot Educ 2007;14:238-43.

44. Mantra I. Indonesia: country report. Promot Educ 1995;2:75-7.

45. Sedyaningsih-Mamahit ER. Client and brothel managers in Kramat Tunggak, Jakarta, Indonesia: Interweaving qualitative studies for planning STD/AIDS prevention programs. South-East Asian J Trop Med Public Health 1997; 28:513-24.

46. Tarantola, D., Mann, J. Viravaidya, M. Moodie, R. and Sundararaman, S. Governments of Asia and Pacific responding to the HIV/AIDS pandemic. AIDS 1994;8:183-98.

47. Viravaidya, M. and Sacks, R. Health and Rural-toUrban migration in Thailand. Med $J$ Australia 1997; 166:152-5.

48. Buasai, S. An organized approach to setting up a health promotion organization in Thailand. Health Promot Matters 1997;1:18-20. 